\title{
The Effectiveness of High-frequency Repetitive Transcranial Magnetic Stimulation in Persistent Somatoform Pain Disorder: A Case Series
}

\author{
Shubh Mohan Singh ${ }^{1}$, Vijay Prakash ${ }^{1}$, Swati Choudhary ${ }^{1}$, Ajit Avasthi ${ }^{1}$ \\ 1. Psychiatry, Postgraduate Institute of Medical Education and Research, Chandigarh, IND
}

Corresponding author: Shubh Mohan Singh, shubhmohan@gmail.com

\begin{abstract}
Somatoform pain disorders (SPD) are common, disabling and do not respond well to existing treatment modalities. We investigated the usefulness of 18 sessions of high frequency repetitive transcranial magnetic stimulation delivered at the left dorsolateral prefrontal cortex (DLPFC) in five right-handed patients with SPD. All patients reported significant improvement in pain relief and activities of daily living. Highfrequency repetitive transcranial magnetic stimulation (rTMS) delivered at the left DLPFC may be useful in SPD.
\end{abstract}

Categories: Pain Management, Psychiatry, Other

Keywords: pain, somatoform, disorder, neuromodulation, repetitive transcranial magnetic stimulation, chronic

\section{Introduction}

Somatoform disorders including somatoform pain disorders (SPD) are among the most common psychiatric disorders and are frequently comorbid with depressive disorders [1]. They are generally recalcitrant and lead to significant dysfunction [1]. Various treatment modalities have been used in SPD but there is little evidence for effective treatments in the same [2]. Repetitive transcranial magnetic stimulation (rTMS) is useful in a variety of chronic painful conditions [3]. We hypothesised that high-frequency (HF) rTMS delivered over the prefrontal cortex (PFC) may be useful in SPD. This is because SPDs are frequently comorbid with depressive disorders and HF rTMS is effective in the latter [4]. Secondly, PFC has been shown to be involved in the pathogenesis of SPD [5]. Finally, PFC HF rTMS has been shown to be effective in reducing pain associated with resistant depression [3]. This study represents a preliminary investigation into the potential effectiveness of HF rTMS in SPD.

Received 04/25/2018 Review began 05/01/2018 Review ended 05/28/2018 Published 06/01/2018

\section{() Copyright 2018} Singh et al. This is an open access article distributed under the terms of the Creative Commons Attribution License CC-BY 3.0., which permits unrestricted use, distribution, and reproduction in any medium, provided the original author and source are credited.

\section{Case Presentation}

The study protocol was passed by the institute ethics committee and the study was carried out in the rTMS service of the department of psychiatry of a tertiary hospital in North India. A prospective, open-label design was adopted. Purposive sampling was used to recruit five patients of either gender and aged at least 18 years referred to the service with a diagnosis of persistent somatoform pain disorder (F45.4) as per the ICD-10. All the patients were referred for rTMS treatment because of inadequate response to conventional treatment (mostly pharmacological). All patients provided written informed consent. History and clinical assessment was reviewed and diagnosis was confirmed. All patients were treated with rTMS as per a commonly used protocol [6]. The F3 location on the scalp was determined as per the 10-20 system. This location generally corresponds to the left dorsolateral prefrontal cortex (DLPFC). Motor threshold was detected using the visual method as per the intensity required to evoke contraction of the Abductor pollicis brevis muscle of the right hand at least $50 \%$ of the times the stimulus was delivered. The pulses were delivered at $100 \%$ of the motor threshold. The rTMS was delivered in form of pulses delivered at a frequency of $10 \mathrm{~Hz}$ for 4 seconds followed by a wait period of 26 seconds (high frequency). We delivered 1200 pulses/session (30 trains/session). One session/day was delivered each working day (Monday-Saturday). We delivered 18 sessions/patient. All treatments were delivered using a figure-of- 8 coil on a Magstim Rapid2 machine. All patients continued to be managed by referring clinicians who could alter pre-existing prescriptions as per requirement. Assessments were carried out at baseline, weekly thereafter until the end of 18 sessions and finally at two weeks after last rTMS session. Pain assessment was done using a 10-cm visual analog scale (VAS). Table 1 presents the patient socio-demographic and clinical profiles and details of response to rTMS. 


\section{Cureus}

\begin{tabular}{|c|c|c|c|c|c|c|c|c|c|c|}
\hline \multirow{2}{*}{$\begin{array}{l}\text { S. } \\
\text { No. }\end{array}$} & \multirow{2}{*}{ Patient profile } & \multirow{2}{*}{$\begin{array}{l}\text { Duration of } \\
\text { symptoms in } \\
\text { years }\end{array}$} & \multirow{2}{*}{$\begin{array}{l}\text { Current } \\
\text { prescription }\end{array}$} & \multirow{2}{*}{$\begin{array}{l}\text { Comorbid } \\
\text { psychiatric } \\
\text { diagnosis }\end{array}$} & \multicolumn{5}{|c|}{ VAS Score } & \multirow{2}{*}{$\begin{array}{l}\% \\
\text { decrease }\end{array}$} \\
\hline & & & & & Baseline & 1 & 2 & 3 & 5 & \\
\hline 1 & $\begin{array}{l}40 \text { years old married female, } \\
\text { illiterate, homemaker, pain over } \\
\text { head, both upper limbs and } \\
\text { trunk }\end{array}$ & 10 years & $\begin{array}{l}\text { Duloxetine } 60 \\
\text { mg/day }\end{array}$ & None & 8 & 8 & 7 & 6 & 6 & 25 \\
\hline 2 & $\begin{array}{l}50 \text { years old married female, } \\
\text { homemaker, illiterate, pain over } \\
\text { head, neck and trunk }\end{array}$ & 2 years & $\begin{array}{l}\text { Duloxetine } 60 \\
\mathrm{mg} / \text { day }\end{array}$ & None & 8 & 8 & 7 & 3 & 3 & 62.5 \\
\hline 3 & $\begin{array}{l}32 \text { years old married male, } 10 \\
\text { years of education, farmer, pain } \\
\text { all over body }\end{array}$ & 15 years & $\begin{array}{l}\text { Venlafaxine } \\
150 \mathrm{mg}\end{array}$ & $\begin{array}{l}\text { Dysthymia } \\
\text { (F34.1) }\end{array}$ & 8 & 8 & 6 & 3 & 3 & 62.5 \\
\hline 4 & $\begin{array}{l}38 \text { years old married female, } \\
\text { illiterate homemaker, pain over } \\
\text { head, abdomen }\end{array}$ & 5 years & $\begin{array}{l}\text { Venlafaxine } 150 \\
\text { mg Duloxetine } \\
60 \mathrm{mg}\end{array}$ & None & 8 & 8 & 6 & 3 & 3 & 62.5 \\
\hline 5 & $\begin{array}{l}43 \text { years old married female, } \\
\text { homemaker, illiterate, pain over } \\
\text { right side of body }\end{array}$ & 18 years & $\begin{array}{l}\text { Duloxetıne } 60 \\
\mathrm{mg}\end{array}$ & $\begin{array}{l}\text { Dissociative } \\
\text { motor disorder } \\
\text { (F44.4) }\end{array}$ & 9 & 9 & 3 & 3 & 2 & 77.77 \\
\hline
\end{tabular}

\section{TABLE 1: Patient profile and response to rTMS.}

VAS: Visual analog scale; rTMS: Repetitive transcranial magnetic stimulation.

All patients were right-handed. None of the patients had any diagnosable physical illness. All patients were able to complete 18 sessions. No serious side-effects were noted or reported.

Our results indicate that HF rTMS delivered over the left DLPFC was effective in our cohort with SPD. The improvement started by the second week (after six sessions) and continued over the rest of the duration of rTMS. Improvement was sustained at two weeks after last session of rTMS. All patients also reported subjective improvements in activities of daily living and that the pain was reduced and bothered them a lot less than before. All patients were satisfied with the treatment. These results are in keeping with other reports that have shown the effectiveness of rTMS in chronic pain [3]. Our study is perhaps the first to report this in SPD.

\section{Discussion}

SPDs are generally poorly researched and have low quality evidence with regards to the effectiveness of treatment options [1]. Both pharmacological and non-pharmacological options have been tried without much success and given the heterogeneity of clinical presentations, specific treatment guidelines are unavailable $[7,8]$. Whereas there is some evidence with respect to the effectiveness of rTMS in pain associated with depressive disorders and disorders such as fibromyalgia or neuropathic pain, to the best of our knowledge no such evidence exists for SPD [9]. Various mechanisms for the putative effectiveness of rTMS in such conditions have been postulated but the exact mechanisms remain unknown. In such a scenario, treatment options such as rTMS in SPD need to be investigated more thoroughly.

Our study found that HF PFC rTMS was effective in alleviating pain in SPD. The speed of improvement was similar to that has been reported in other trials for chronic pain due to fibromyalgia [10]. Thus similar mechanisms such as endogenous opioid release and functional improvements in brain areas associated with pain may be involved [9]. We also found that our patients reported a greater quantum of improvement than has been reported elsewhere. For instance, in a study on medically unexplained pain in patients with resistant depression, the improvement reported was 37.5\% [11]. In our study, except for one patient all patients reported an improvement of at least $62.5 \%$. These results must be seen in context of socioeducational background of the patients. It is well known that rTMS is associated with significant placebo response including in pain disorders [12]. It is likely that in our study as well, placebo response may have played an important part in the reported improvement.

\section{Conclusions}

Our study indicates that rTMS needs to be investigated more thoroughly as a treatment option in SPD. This 


\section{Additional Information}

\section{Disclosures}

Human subjects: Consent was obtained or waived by all participants in this study. Institutional Ethics Committee PGIMER Chandigarh issued approval INT/IEC/2017/88. Conflicts of interest: In compliance with the ICMJE uniform disclosure form, all authors declare the following: Payment/services info: All authors have declared that no financial support was received from any organization for the submitted work. Financial relationships: All authors have declared that they have no financial relationships at present or within the previous three years with any organizations that might have an interest in the submitted work. Other relationships: All authors have declared that there are no other relationships or activities that could appear to have influenced the submitted work.

\section{References}

1. Bass C, Peveler R, House A: Somatoform disorders: severe psychiatric illnesses neglected by psychiatrists . $\mathrm{Br}$ J Psychiatry. 2001, 179:11-14. 10.1192/bjp.179.1.11

2. Kroenke K: Efficacy of treatment for somatoform disorders: a review of randomized controlled trials . Psychosom Med. 2007, 69:881-888. 10.1097/PSY.0b013e31815b00c4

3. Goudra B, Shah D, Balu G, Gouda G, Balu A, Borle A, Singh PM: Repetitive transcranial magnetic stimulation in chronic pain: a meta-analysis. Anesth Essays Res. 2017, 11:751-757. 10.4103/aer.AER_10_17

4. Lefaucheur J-P, André-Obadia N, Antal A, et al.: Evidence-based guidelines on the therapeutic use of repetitive transcranial magnetic stimulation (rTMS). Clin Neurophysiol. 2014, 125:2150-2206. 10.1016/j.clinph.2014.05.021

5. Valet M, Gündel H, Sprenger T, et al.: Patients with pain disorder show gray-matter loss in pain-processing structures: a voxel-based morphometric study. Psychosom Med. 2009, 71:49-56. 10.1097/PSY.0b013e31818d1e02

6. George MS, Lisanby SH, Avery D, et al.: Daily left prefrontal transcranial magnetic stimulation therapy for major depressive disorder: a sham-controlled randomized trial. Arch Gen Psychiatry. 2010, 67:507-516. 10.1001/archgenpsychiatry.2010.46

7. van Dessel N, den Boeft M, van der Wouden JC, et al.: Non-pharmacological interventions for somatoform disorders and medically unexplained physical symptoms (MUPS) in adults. Cochrane Database Syst Rev. 2014, CD011142. 10.1002/14651858.CD011142.pub2

8. Kleinstäuber M, Witthöft M, Steffanowski A, van Marwijk H, Hiller W, Lambert MJ: Pharmacological interventions for somatoform disorders in adults. Cochrane Database Syst Rev. 2014, CD010628. 10.1002/14651858.CD010628.pub2

9. Li CT, Su TP, Hsieh JC, Ho ST: Efficacy and practical issues of repetitive transcranial magnetic stimulation on chronic medically unexplained symptoms of pain. Acta Anaesthesiol Taiwan. 2013, 51:81-87. 10.1016/j.aat.2013.06.003

10. Galhardoni R, Correia GS, Araujo H, et al.: Repetitive transcranial magnetic stimulation in chronic pain: a review of the literature. Arch Phys Med Rehabil. 2015, 96:156-172. 10.1016/j.apmr.2014.11.010

11. Li C-T, Lin W-C, Chen M-H, Su T-P, Bai Y-M, Hsieh J-C: Analgesic effect of repetitive transcranial magnetic stimulation on medically unexplained pain in patients with medication-resistant depression. Taiwan J Psychiatry. 2016, 30:34-44

12. André-Obadia N, Magnin M, Garcia-Larrea L: On the importance of placebo timing in rTMS studies for pain relief. Pain. 2011, 152:1233-1237. 10.1016/j.pain.2010.12.027 